\title{
Differential Regional Expression and Ultrastructural Localization of $\alpha$-Actinin-2, a Putative NMDA Receptor-Anchoring Protein, in Rat Brain
}

\author{
Michael Wyszynski, ${ }^{1}$ Viktor Kharazia, ${ }^{2}$ Roopal Shanghvi, ${ }^{1}$ Anuradha Rao, ${ }^{3}$ Alan H. Beggs, ${ }^{4}$ Ann Marie Craig, ${ }^{3}$ \\ Richard Weinberg, ${ }^{2}$ and Morgan Sheng ${ }^{1}$ \\ ${ }_{1}^{1}$ Howard Hughes Medical Institute and Department of Neurobiology, Massachusetts General Hospital and Harvard \\ Medical School, Boston, Massachusetts 02114, 2Department of Cell Biology and Anatomy, University of North Carolina \\ at Chapel Hill, Chapel Hill, North Carolina 27599, ${ }^{3}$ Department of Cell and Structural Biology, University of Illinois, Urbana- \\ Champaign, Illinois 61801, and 'Genetics Division, Children's Hospital and Harvard Medical School, \\ Boston, Massachusetts 02115
}

\begin{abstract}
Fast chemical neurotransmission is dependent on ionotropic receptors that are concentrated and immobilized at specific postsynaptic sites. The mechanisms of receptor clustering and anchoring in neuronal synapses are poorly understood but presumably involve molecular linkage of membrane receptor proteins to the postsynaptic cytoskeleton. Recently the actinbinding protein $\alpha$-actinin-2 was shown to bind directly to the NMDA receptor subunits NR1 and NR2B (Wyszynski et al., 1997), suggesting that $\alpha$-actinin-2 may function to attach NMDA receptors to the actin cytoskeleton. Here we show that $\alpha$-actinin-2 is localized specifically in glutamatergic synapses in cultured hippocampal neurons. By immunogold electron microscopy, $\alpha$-actinin-2 is concentrated over the postsynaptic density (PSD) of numerous asymmetric synapses where it colocalizes with NR1 immunoreactivity. Thus $\alpha$-actinin-2 is appro-
\end{abstract}

priately positioned at the ultrastructural level to function as a postsynaptic-anchoring protein for NMDA receptors. $\alpha$-Actinin-2 is not, however, exclusively found at the PSD; immunogold labeling was also associated with filaments and the spine apparatus of dendritic spines and with microtubules in dendritic shafts. $\alpha$-Actinin-2 showed marked differential regional expression in rat brain. For instance, the protein is expressed at much higher levels in dentate gyrus than in area CA1 of the hippocampus. This differential regional expression implies that glutamatergic synapses in various parts of the brain differ with respect to their $\alpha$-actinin- 2 content and thus, potentially, the extent of possible interaction between $\alpha$-actinin- 2 and the NMDA receptor.

Key words: $\alpha$-actinin; NMDA receptor; GKAP; glutamatergic synapses; postsynaptic density; actin cytoskeleton
The NMDA receptor subclass of ionotropic glutamate receptors has been implicated in the mechanisms of synaptogenesis, synaptic plasticity, and excitotoxicity (Constantine-Paton et al., 1990; Bliss and Collingridge, 1993; Choi, 1995). Like other ionotropic glutamate receptors, NMDA receptors are concentrated at postsynaptic sites in glutamatergic synapses. The molecular mechanisms by which neurotransmitter receptors are clustered and immobilized at synaptic locations is an active area of research that promises to reveal new insights into the structural and functional organization of synapses.

NMDA receptor activity in neurons exhibits mechanosensitivity (Paoletti and Ascher, 1994) and is dependent on the integrity of filamentous actin (F-actin) (Rosenmund and Westbrook, 1993), suggesting a functionally important interaction between NMDA receptors and the postsynaptic actin cytoskeleton. A number of intracellular proteins may link NMDA receptors to the

Received Oct. 6, 1997; revised Dec. 1, 1997; accepted Dec. 1, 1997.

This research was supported by National Research Service Award CA66268-02 from the National Institutes of Health (M.W.), National Institutes of Health Grants NS35050 (M.S.) and NS29879 (R.W.), Grant AR44345 from the National Institute of Arthritis and Musculoskeletal and Skin Diseases (A.H.B.), and a grant from the Muscular Dystrophy Association (A.H.B.). M.S. is an Assistant Investigator of the Howard Hughes Medical Institute.

Correspondence should be addressed to Dr. Morgan Sheng, Howard Hughes Medical Institute (Wellman 423), Massachusetts General Hospital, 50 Blossom Street, Boston, MA 02114.

Copyright (C) 1998 Society for Neuroscience $\quad 0270-6474 / 98 / 181383-10 \$ 05.00 / 0$ cytoskeleton. For instance, the NMDA receptor subunit NR2 binds to the postsynaptic density (PSD)-95 family of putative ion channel-clustering proteins (Kornau et al., 1995; Niethammer et al., 1996; Sheng and Kim, 1996), but whether this interaction links NMDA receptors to the cytoskeleton is unclear. More recently, $\alpha$-actinin-2, a member of the spectrin/dystrophin family of actinbinding proteins, was shown to bind directly to the NMDA receptor subunits $\mathrm{NR} 1$ and $\mathrm{NR} 2 \mathrm{~B}$ using yeast two-hybrid and in vitro binding assays (Wyszynski et al., 1997). Given that $\alpha$-actinins are actin-binding proteins, we hypothesized that $\alpha$-actinin-2 might function as a bridging protein between NMDA receptors and actin at postsynaptic sites. Some circumstantial evidence of this has been obtained in neurons. At the light microscopic level in cultured hippocampal neurons, $\alpha$-actinin- 2 shows punctate colocalization with NMDA receptors at presumptive synaptic sites (Wyszynski et al., 1997). In addition, $\alpha$-actinin-2 can be coimmunoprecipitated in a complex with NMDA receptors from rat brain (Wyszynski et al., 1997). However, the subcellular localization of $\alpha$-actinin- 2 has not been studied in detail in vivo. The present study tests this hypothesis by asking whether $\alpha$-actinin-2 is specifically concentrated in the PSD of glutamatergic synapses in rat brain and by investigating whether $\alpha$-actinin- 2 colocalizes with the NMDA receptor at the ultrastructural level. We also provide here the first report on the developmental and spatial patterns of $\alpha$-actinin- 2 expression in rat brain. Interestingly, $\alpha$-actinin-2 protein exhibits marked differential regional expres- 
sion in rat brain, implying molecular heterogeneity of glutamatergic synapses in different parts of the CNS.

\section{MATERIALS AND METHODS}

Antibodies, expression constructs, and immunoblotting. Antibodies against $\alpha$-actinin-2, NR2B, and PSD-95 have been described (Sheng et al., 1994; Kim et al., 1995; Wyszynski et al., 1997). Monoclonal anti-Ca ${ }^{2+}$ calmodulin-dependent protein kinase II antibody (Chemicon, Temecula, CA) and anti-NR1 monoclonal antibodies 54.1 (PharMingen, San Diego, CA) were used for immunoblotting at $1 \mu \mathrm{g} / \mathrm{ml}$. $\alpha$-Actinin-2 and $\alpha$-actinin-3 expression constructs were prepared by subcloning the fulllength cDNAs for $\alpha$-actinin- 2 or $\alpha$-actinin-3 into the EcoRI site of the mammalian expression vector pcDNA3 (Invitrogen, San Diego, CA). COS-7 cells were transfected using the lipofectamine method (Life Technologies, Grand Island, NY). Preparation and immunoblotting of COS-7 cell lysates and brain membranes were performed as described (Kim et al., 1997). All proteins were visualized using peroxidaseconjugated secondary antibodies and enhanced chemiluminescence (ECL) (Amersham, Arlington Heights, IL).

Immunohistochemistry on brain and cultured neurons. Immunohistochemistry on floating $50 \mu \mathrm{m}$ brain sections was performed as described (Kim et al., 1996) and was visualized using the Vectastain ABC kit (Vector Laboratories, Burlingame, CA) and diaminobenzidine (DAB) or using Cy3- or FITC-conjugated secondary antibodies (Jackson ImmunoResearch, West Grove, PA). Hippocampal neuronal cultures were prepared as described (Goslin and Banker, 1991). Primary antibodies were used at the following concentrations: 4B2 $(1 \mu \mathrm{g} / \mathrm{ml})$, EA-53 (1: 20,000 dilution; Sigma, St Louis, MO), anti-GAD monoclonal antibodies (1 $\mu \mathrm{g} / \mathrm{ml}$; Boehringer Mannheim, Indianapolis, IN), and anti-GAD-6 monoclonal antibodies (1:2 dilution; Developmental Studies Hybridoma Bank, University of Iowa, Iowa City, IA); antibodies were visualized with FITC- and Cy3-conjugated secondary antibodies $(2.5 \mu \mathrm{g} / \mathrm{ml}$; Jackson ImmunoResearch) for rat brain sections and with FITC- and Texas Red-conjugated secondary antibodies ( $1 \mu \mathrm{g} / \mathrm{ml}$; Vector Laboratories) for cultured hippocampal neurons. DAB brain sections and cultured hippocampal neurons were viewed using a Zeiss Axioskop microscope; fluorescent brain images were recorded using a BioRad MRC 1000 confocal microscope.

Electron microscopy. Male Sprague Dawley rats (200-350 gm) were anesthetized with pentobarbital $(60 \mathrm{mg} / \mathrm{kg})$, briefly flushed with heparinized saline, and perfused intra-aortically with $0.1 \mathrm{M}$ phosphate buffer, pH 7.4 (PB), containing 4\% freshly depolymerized paraformaldehyde and either $0.1 \%$ glutaraldehyde (for immunoperoxidase labeling) or $2 \%$ paraformaldehyde and $2 \%$ glutaraldehyde (for immunogold labeling). Forty-micrometer-thick frontal sections from brain were cut using a vibratome and collected in PB.

Pre-embedding immunoperoxidase staining for electron microscopy was performed using mouse monoclonal $\alpha$-actinin antibody EA-53. Sections were pretreated sequentially in $1 \%$ sodium borohydride, $50 \%$ ethanol, and 3\% hydrogen peroxide in PBS and then blocked in $10 \%$ normal donkey serum. Sections were then incubated sequentially in EA-53 (diluted 1:50,000-80,000 in PBS containing 0.01\% Triton X-100) overnight, biotinylated donkey anti-mouse serum (1:250 dilution; Jackson ImmunoResearch) for $2 \mathrm{hr}$, and ExtraAvidin-peroxidase complex (1: 5,000 dilution; Sigma) for $1 \mathrm{hr}$. After revealing the peroxidase with nickel-enhanced diaminobenzidine, sections were osmicated, stained en bloc in uranyl acetate, and wafer-embedded in Epon-Spurr resin or, for combining with postembedding immunogold labeling, were processed without osmium (as described below). To stabilize immunoperoxidase in the absence of osmium, we incubated sections in platinum chloride $(0.5 \%$ in $0.1 \mathrm{M}$ maleate buffer) before embedding.

For postembedding immunogold, sections were embedded as described by Phend et al. (1995). Briefly, sections were treated sequentially over ice in $1 \%$ tannic acid in $0.1 \mathrm{M}$ maleate buffer, $\mathrm{pH} 6.0 ; 1 \%$ uranyl acetate; $0.5 \%$ iridium tetrabromide (Pfaltz and Bauer, Waterbury, CT); 50 and $70 \%$ ethanol; $1 \%$ phenylenediamine hydrochloride in $70 \%$ ethanol; and $1 \%$ uranyl acetate in $70 \%$ ethanol and then dehydrated in 80, 95, and $100 \%$ ethanol. Sections were then immersed in propylene oxide and infiltrated with Epon-Spurr resin. After overnight infiltration in resin, sections were sandwiched between strips of Aclar plastic film, flattened between microscope slides, and polymerized at $60^{\circ} \mathrm{C}$ for $36 \mathrm{hr}$. Chips from layers II-III of S1 cortex were glued onto plastic blocks. Thin sections $(\sim 100 \mathrm{~nm})$ were cut, collected on 300-mesh uncoated nickel grids, and treated with Quick-Coat (Kiyota Express, Elk Grove, IL) for improved section adhesion.
For single-labeling, polyclonal $\alpha$-actinin-2 specific antibodies 4B2 (Wyszynski et al., 1997) were used as described (Phend et al., 1995). Briefly, grids were washed with Tris-buffered saline containing $0.005 \%$ Tergitol NP-10 (TBS/T) at pH 7.6, incubated at $37^{\circ} \mathrm{C}$ overnight in TBS/T containing a 1:8,000-10,000 dilution of 4B2, rinsed in TBS/T at $\mathrm{pH} 7.6$, transferred to TBS/T at $\mathrm{pH} 8.2$, and incubated in TBS/T containing a 1:20 dilution of secondary gold-conjugated antibody IgG-conjugated to $18 \mathrm{~nm}$ gold particles (Jackson ImmunoResearch) or to $F(a b)$ fragments conjugated to $1.4 \mathrm{~nm}$ gold particles (NanoProbes, Stoney Brook, NY). The $1.4 \mathrm{~nm}$ particles were visualized by silver intensification using an HQ silver kit (NanoProbes).

For the colocalization of $\alpha$-actinin-2 with the NMDA receptor subunit NMDAR1 and guanylate kinase-associated protein, either postembedding immunogold on material processed previously with pre-embedding immunoperoxidase or postembedding immunogold with two antibodies in adjacent thin sections was performed. Postembedding was performed as described above using a 1:300 dilution of rabbit polyclonal antiNMDAR1 antibodies (Petralia et al., 1994), a 1:300 dilution of affinitypurified rabbit polyclonal anti-GKAP antibodies (Naisbitt et al., 1997), and a 1:8000 dilution of the rabbit polyclonal $\alpha$-actinin-2 specific antibodies 4B2 (Wyszynski et al., 1997). Immunoperoxidase labeling was performed as described above using a 1:50,000 dilution of mouse monoclonal $\alpha$-actinin specific antibodies (EA-53). After immunocytochemical processing, grids were air-dried, stained with uranyl acetate and Sato's lead, and examined with a JEOL CX200 transmission electron microscope at $80 \mathrm{kV}$. Virtually no gold particles were seen if the primary antibody was omitted from the procedure, and no selective labeling of spines or synaptic structures was seen if preimmune rabbit serum was substituted for the rabbit polyclonal antisera.

\section{RESULTS}

\section{Regional and developmental expression of $\alpha$-actinin-2 in rat brain}

To investigate the expression of $\alpha$-actinin- 2 protein in rat brain, we generated anti-peptide antibodies (termed 4B2) against a region of $\alpha$-actinin- 2 that is not conserved in other members of the $\alpha$-actinin family of proteins (Wyszynski et al., 1997). To confirm specificity of the 4B2 antibody, we transiently transfected COS-7 cells with either $\alpha$-actinin- 2 or $\alpha$-actinin-3 cDNAs and fluorescently stained these cells with 4B2 antibodies. 4B2 immunoreactivity was observed in COS-7 cells expressing $\alpha$-actinin-2 but not $\alpha$-actinin-3 protein (Fig. $1 A$ ). As a control, $\alpha$-actinin-3 expression was confirmed in these cells using anti-peptide antibodies (termed 5B2) that are specific for $\alpha$-actinin-3 (Fig. 1 $A$ ). Similarly, by immunoblotting, 4B2 recognized $\alpha$-actinin- 2 but not $\alpha$-actinin-3 protein expressed heterologously in COS-7 cells, whereas $\alpha$-actinin-3-specific antibodies showed the reverse specificity of detection (Fig. 1B). Thus 4B2 can specifically recognize $\alpha$-actinin- 2 by both immunostaining and immunoblotting. In addition to $4 \mathrm{~B} 2$, we took advantage of an independent antibody raised against $\alpha$-actinin-2 and -3 (mouse monoclonal EA-53). Because $\alpha$-actinin-3 is not expressed in the brain (Fig. $1 B)($ A. H. Beggs, unpublished observations), EA-53 antibodies should be specific for $\alpha$-actinin-2 in rat brain. On immunoblots of rat brain membranes, both 4B2 and EA-53 antibodies react with a single band of $\sim 100 \mathrm{kDa}$ molecular weight, consistent with the known and predicted size of $\alpha$-actinin-2 (Beggs et al., 1992) (Fig. 1C). The fact that the same band is recognized by two independent antibodies is strong evidence that this $100 \mathrm{kDa}$ band represents $\alpha$-actinin-2 protein. 5B2 ( $\alpha$-actinin-3) antibodies failed to detect any bands in rat brain (Fig. $1 B$ ).

By Western blot analysis, $\alpha$-actinin-2 is found abundantly in crude synaptosomal membrane fractions from neocortex, hippocampus, and subcortical regions but at low levels in cerebellum (Fig. 2A). This regional pattern of expression is similar to that of $\mathrm{NR} 1$ and of the $\alpha$-subunit of $\mathrm{Ca}^{2+} /$ calmodulin-dependent protein kinase II (CaMKII), both of which are relatively concentrated in 


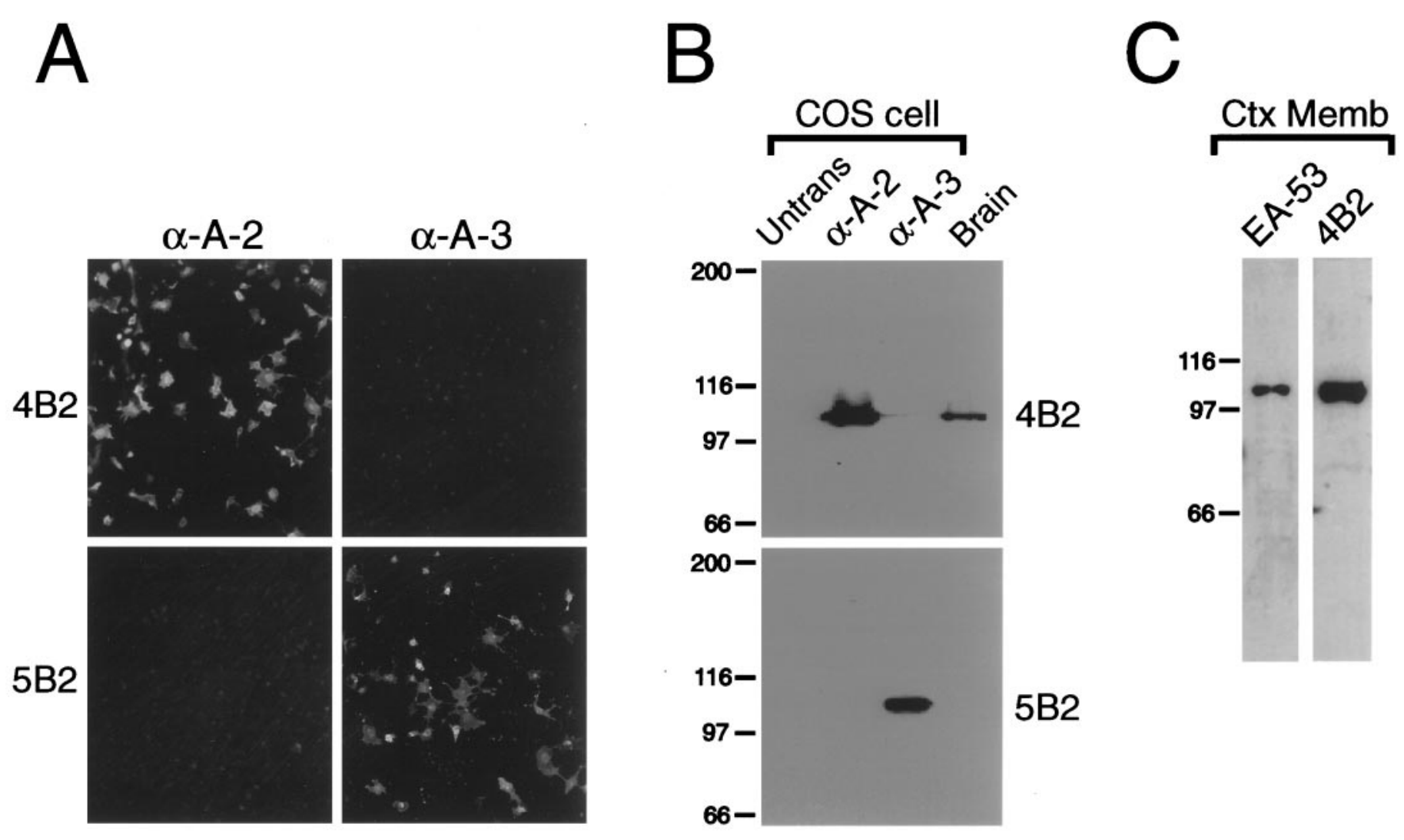

Figure 1. Specificity of $\alpha$-actinin-2 antibodies (4B2) and $\alpha$-actinin-3 antibodies (5B2). $A$, COS-7 cells transfected with $\alpha$-actinin-2 or $\alpha$-actinin-3 expression constructs were stained with $4 B 2$, which specifically recognizes $\alpha$-actinin-2 and not $\alpha$-actinin-3, or with $5 B 2$, which specifically reacts with $\alpha$-actinin-3 and not $\alpha$-actinin-2. B, Western blot analysis of COS-7 cells transfected with $\alpha$-actinin-2 or $\alpha$-actinin-3 (Untrans, untransfected COS-7 cell control) and of a crude synaptosomal membrane fraction from rat whole brain (10 $\mu$ g of protein) is shown. $4 B 2$ recognizes $\alpha$-actinin-2 but not $\alpha$-actinin-3 protein expressed heterologously in COS-7 cells and a $100 \mathrm{kDa}$ band in brain. $5 B 2$ recognizes $\alpha$-actinin- 3 in COS-7 cells but detects no band in brain. $C$, Crude synaptosomal membrane fraction from rat cortex (Ctx Memb; $10 \mu \mathrm{g}$ of protein) was separated by SDS-PAGE and immunoblotted for $\alpha$-actinin-2 using $E A-53$ or $4 B 2$ antibodies. Both antibodies recognize the same $100 \mathrm{kDa}$ band. Positions of molecular weight markers are shown in kilodaltons. $\alpha-A$-2, $\alpha$-Actinin-2; $\alpha-A-3, \alpha$-actinin-3.

forebrain (Fig. 2A). However, in contrast to NR1, a significant proportion of $\alpha$-actinin-2 fractionates into the soluble S100 supernatant fraction of brain homogenate (Fig. $2 B$ ).

During postnatal development, $\alpha$-actinin- 2 protein is already detectable in neonatal rat cerebral cortex [age, postnatal day 1 (P1)] but increases during the next 2 weeks to reach high levels of expression by $\sim 2$ weeks after birth (Fig. $2 C$ ). The temporal pattern of $\alpha$-actinin- 2 expression is similar to that of NR1 and PSD-95 (Fig. 2C), two proteins of the postsynaptic density that are complexed with $\alpha$-actinin-2 in vivo (Wyszynski et al., 1997). In contrast, NR2B (a modulatory NMDA receptor subunit that also binds directly to $\alpha$-actinin-2) is present at approximately equal amounts throughout the postnatal period (Fig. 2C). The increase in NR1 and PSD-95 expression and the stable expression of NR2B are in agreement with previous findings (Cho et al., 1992; Sheng et al., 1994). Thus during the first 2 weeks of postnatal development, there is a parallel induction in the expression of $\alpha$-actinin-2, NR1, and PSD-95 proteins, coincident with an active period of synaptogenesis in the cortex.

\section{Immunohistochemical localization of $\alpha$-actinin-2 in rat brain}

The previous study of $\alpha$-actinin-2 focused on immunolocalization in cultured hippocampal neurons (Wyszynski et al., 1997). In this study EA-53 and 4B2 antibodies were used for immunohisto- chemical localization of $\alpha$-actinin- 2 at the cellular and subcellular levels in adult rat brain. These independent antibodies gave essentially identical staining patterns, suggesting that they recognize the true distribution of $\alpha$-actinin- 2 protein. Results using EA-53 are primarily shown here because this monoclonal antibody gave a higher signal-to-noise ratio.

Light microscopic immunocytochemistry reveals that $\alpha$-actinin-2 protein is differentially expressed in different regions of the brain (Fig. 3). Staining is prominent in forebrain structures, particularly in the striatum, hippocampus, and cortex (Fig. $3 A$ ). In the neocortex, $\alpha$-actinin-2 staining shows layer specificity, being strongest in layers II/III and V and weak in layer IV (Fig. $3 B$ ). At the cellular level in cortex, expression of $\alpha$-actinin- 2 is prominent in pyramidal neurons and in scattered interneurons. Immunoreactivity is prominent in the dendritic processes of pyramidal neurons and relatively absent from their cell bodies, which stand out as "holes" against the neuropil staining (see Fig. 3G). $\alpha$-Actinin-2 immunoreactivity is strikingly punctate in character both on pyramidal cell dendrites (Fig. 3C) and in the neuropil of the neocortex (best demonstrated by immunofluorescence confocal microscopy; Fig. $3 G$ ). The pattern of punctate $\alpha$-actinin-2 staining along apical dendrites suggests localization in dendritic spines (Fig. 3C). In contrast, scattered interneurons in cerebral cortex are intensely immunoreactive for $\alpha$-actinin- 2 in their so- 


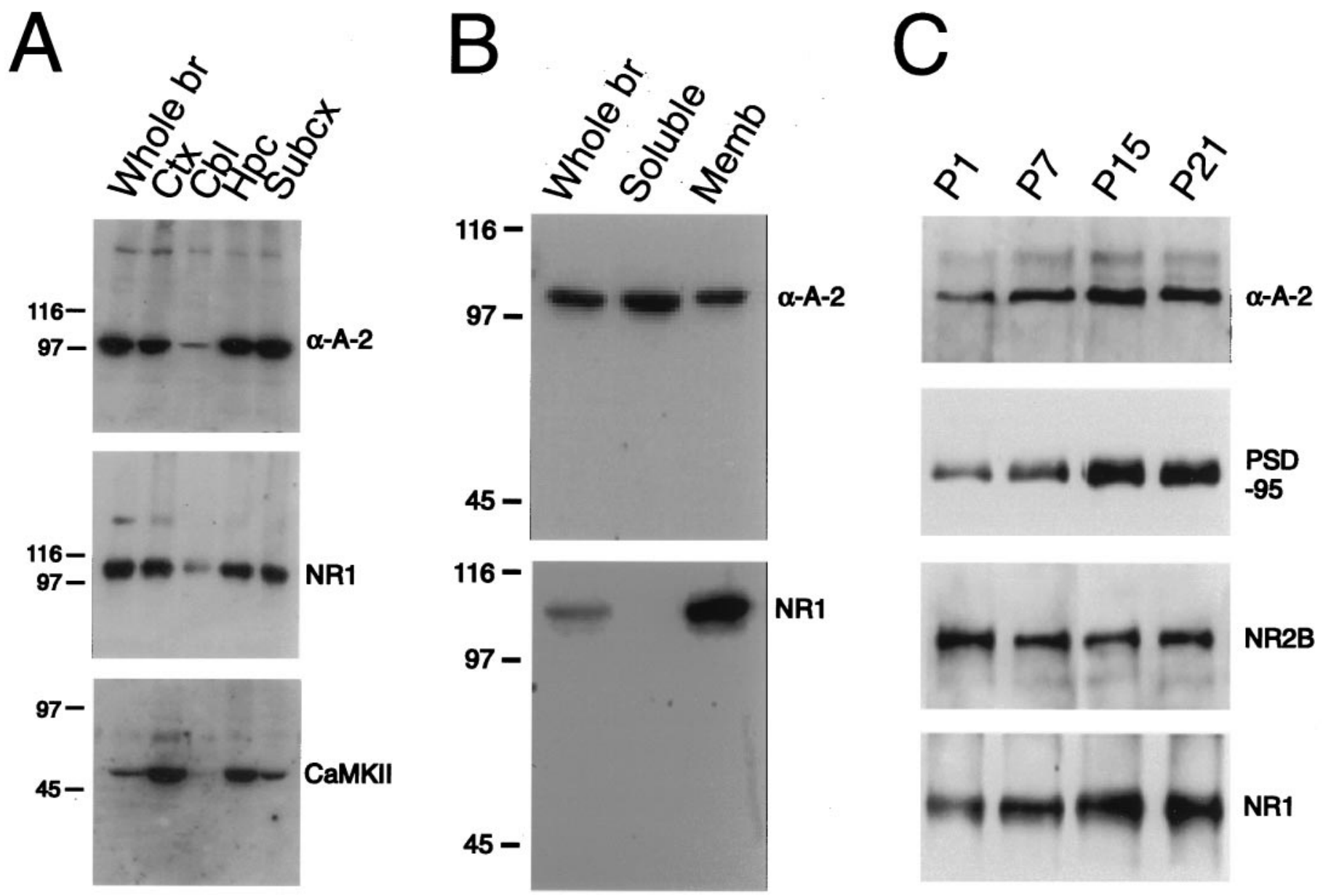

Figure 2. Immunoblot analysis of $\alpha$-actinin-2 protein expression in rat brain. $A$, Differential regional expression of $\alpha$-actinin-2 in rat brain analyzed by immunoblotting with 4B2 antibodies. Expression of $\alpha$-actinin-2 $(\alpha-A-2)$ is high in crude synaptosomal membrane fractions from cortex $(C t x)$, hippocampus $(H p c)$, and subcortical regions $(S u b c x)$ but very low in cerebellum $(C b l)$. Equal amounts of protein $(10 \mu \mathrm{g})$ were loaded in each lane. The regional expression patterns of NR1 and the $\alpha$-subunit of $\mathrm{Ca}^{2+} /$ calmodulin-dependent protein kinase II (CaMKII) are shown for comparison. $B$, Presence of $\alpha$-actinin-2 in membrane and soluble fractions of rat brain. Lanes were loaded with rat brain fractions as follows: Whole br (total brain homogenate; $20 \mu \mathrm{g}$ of protein), Soluble (S100 supernatant fraction of brain homogenate; $30 \mu \mathrm{g}$ of protein), and Memb (crude synaptosomal membrane fraction; $10 \mu \mathrm{g}$ of protein). Equal percentages, rather than equal mass, of membrane and soluble fractions were loaded (the soluble fraction contained a threefold higher concentration of total protein than did the membrane fraction). Filters were probed with $\alpha$-actinin-2 4B2 antibodies or with NR1 antibodies. Unlike NR1 protein, a significant amount of $\alpha$-actinin-2 protein from brain is present in the soluble fraction. $C$, Expression of $\alpha$-actinin-2 protein during postnatal cortical development compared with the expression of PSD-95, NR2B, and NR1 proteins. An equal mass (20 $\mu \mathrm{g}$ of protein) of cortical membranes from various ages were immunoblotted for $\alpha$-actinin-2. The same immunoblot filter was stripped and reprobed with the PSD-95, NR2B, and NR1 antibodies. $\alpha$-Actinin-2 protein expression increases to adult levels during the first 2 weeks of postnatal development, as do PSD-95 and NR1 expressions. Numbers indicate the postnatal age of rats in days. Positions of molecular weight markers are shown in kilodaltons.

mata as well as in their dendritic processes (Fig. 3B,E,F). Somatodendritic $\alpha$-actinin-2 immunostaining is also prominent in cells of the striatum (Fig. $3 H$ ). Diencephalic staining is seen in the thalamic reticular nucleus and lateral hypothalamic nuclei (data not shown). In the midbrain, staining is prominent in substantia nigra (Fig. $3 A$ ). In the cerebellum, $\alpha$-actinin- 2 immunostaining is very weak (Fig. 3I), consistent with the low level indicated by immunoblotting (Fig. 2A). In general, white matter and glial cells showed no $\alpha$-actinin-2 labeling.

In the hippocampal formation, $\alpha$-actinin- 2 protein is expressed throughout the dendritic fields of all regions (Fig. $4 A$ ), but staining is strongest in the molecular layer of dentate gyrus and in area CA2 (Figs. 3A, 4A). As observed in neocortex, the cell bodies of hippocampal pyramidal neurons are relatively unstained, whereas the dendrites of these neurons show dense $\alpha$-actinin- 2 immunoreactivity that is remarkably punctate when viewed by high reso- lution confocal microscopy (Fig. 4C). As seen in the cerebral cortex, scattered interneurons in the hippocampal region are heavily labeled for $\alpha$-actinin-2 (data not shown).

In addition to the punctate dendritic and neuropil staining found in both neocortex and hippocampus, we reproducibly observed a curious pattern of bright $\alpha$-actinin-2 immunoreactivity extending a short distance from the base of pyramidal neurons. Best seen in layer $\mathrm{V}$ pyramidal neurons, it often resembled a short dashed line, perhaps corresponding to the path of the initial axon segment of these neurons (see Figs. 3D, 5E). Alternatively, it may reflect intradendritic staining (A. Rao and A. M. Craig, unpublished observations). A similar bright dashed line pattern of $\alpha$-actinin-2 staining could be seen in the hippocampus, interspersed among the cell bodies of the pyramidal and granule cell layers (Fig. 4B). This pattern of $\alpha$-actinin-2 staining was noted with both EA-53 and 4B2 antibodies. 

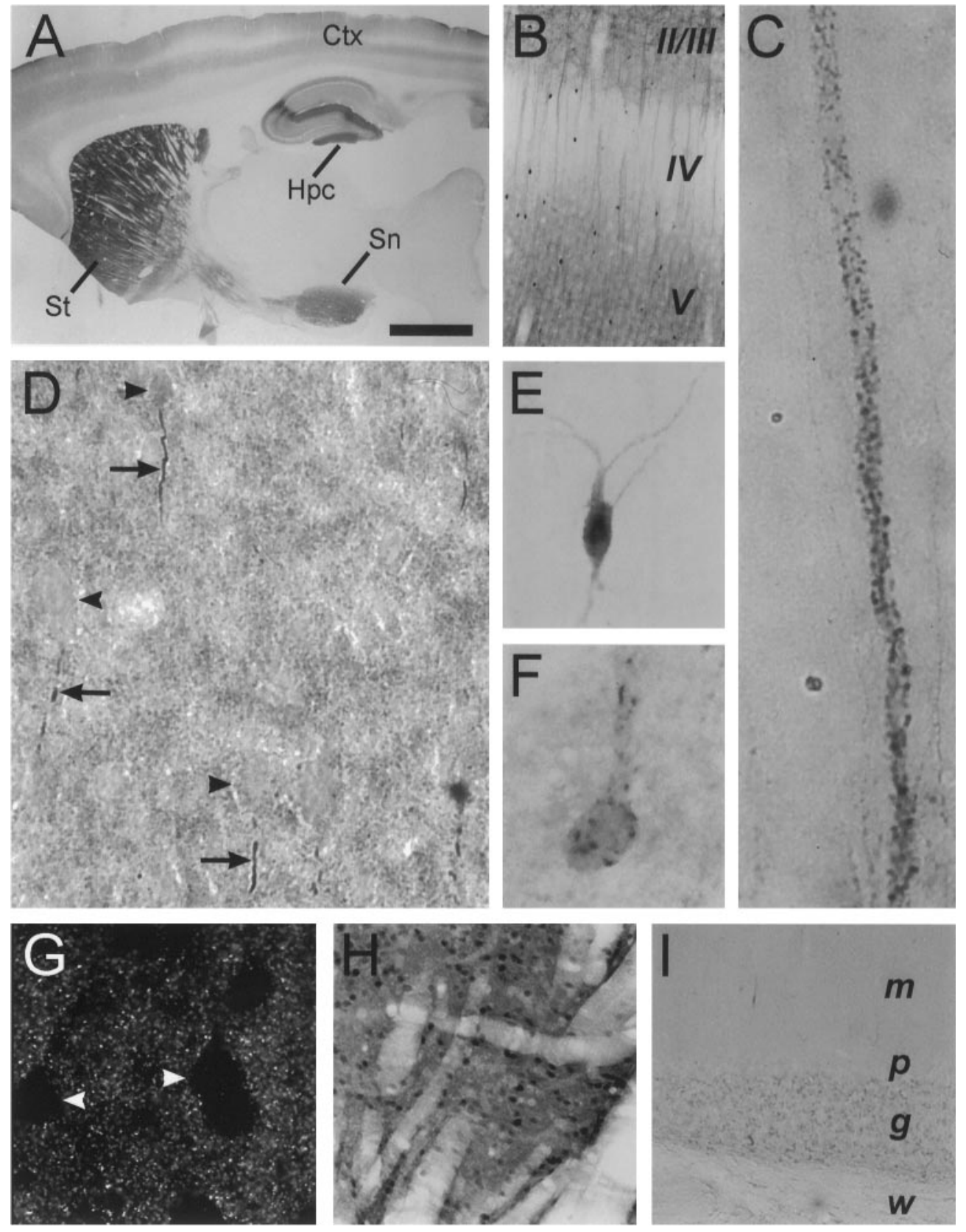

Figure 3. Immunohistochemical localization of $\alpha$-actinin-2 protein in adult rat brain. $A-I$, Sagittal $(A, B, H$, $I)$ and coronal $(C-G)$ sections labeled with $\alpha$-actinin-2 antibody EA-53 and visualized via immunoperoxidase $(A-F, H, I)$ and immunofluorescence $(G)$ labeling. $A$, Low resolution micrograph of a rat brain sagittal section showing $\alpha$-actinin-2 staining particularly in the striatum $(S t)$, cortex $(C t x)$, hippocampus $(H p c)$, and substantia nigra $(S n)$. B, Layer-specific expression in cerebral cortex with predominent $\alpha$-actinin-2 staining in layers II/ III and V. Note the $\alpha$-actinin-2-stained apical dendrites emanating from layer $\mathrm{V}$ pyramidal neurons and the low levels of staining in layer IV neuropil. Dark dots in the micrograph represent intensely labeled cell bodies of a population of interneurons. $C$, Highmagnification view of $\alpha$-actinin-2 immunoreactive puncta decorating apical dendrites of layer $\mathrm{V}$ pyramidal neurons. $D$, Cortical layer $\mathrm{V}$ showing $\alpha$-actinin-2 immunoreactive processes (arrows) extending a short distance from the base of pyramidal cell bodies (arrowheads). $E, F$, Intense $\alpha$-actinin-2 staining in scattered cortical interneurons showing diff use $(E)$ and punctate $(F)$ somatodendritic staining patterns. $G$, High resolution fluorescence confocal micrograph of cortical layer $\mathrm{V}$ showing punctate nature of $\alpha$-actinin-2 immunoreactivity in neuropil. Cell bodies (arrowheads) are relatively spared of $\alpha$-actinin-2 staining. $H$, Dense $\alpha$-actinin-2 immunostaining in cells of the striatum. $I, \alpha$-Actinin-2 immunostaining in the cerebellum that is very weak or undetectable. $m$, Molecular layer; $p$, Purkinje cell body layer; $g$, granular layer; $w$, white matter. Scale bars: $A, 2.5 \mathrm{~mm} ; B, H, 300 \mu \mathrm{m} ; I$, $150 \mu \mathrm{m} ; C, D, G, 50 \mu \mathrm{m} ; E, F, 30 \mu \mathrm{m}$.

\section{Selective localization of $\alpha$-actinin-2 at glutamatergic synapses}

$\alpha$-Actinin-2 binds directly to NMDA receptors, and its immunocytochemical distribution overlaps with NMDA receptors at synaptic sites in cultured neurons (Wyszynski et al., 1997). The highly punctate pattern of $\alpha$-actinin- 2 staining on pyramidal cell dendrites in rat brain is consistent with its localization at dendritic spines (Figs. 3C, $G, 4 C$ ). An important question raised by these findings is whether $\alpha$-actinin- 2 is present specifically in synapses containing NMDA receptors (that is, glutamatergic synapses) or whether it is a general postsynaptic protein present also in other kinds of synapses such as GABAergic synapses. This question is best addressed in cultured neurons, in which individual synapses are easier to resolve than in brain sections.

In primary cultures of hippocampal neurons, $\alpha$-actinin- 2 staining was present in a punctate pattern often corresponding to dendritic spines (Fig. $5 A$ ). The spiny $\alpha$-actinin- 2 clusters overlapped extensively with clusters of GluR1, an AMPA-type glutamate receptor subunit (Fig. $5 A-C$ ). In contrast, $\alpha$-actinin-2 immunoreactivity shows no detectable overlap with that of glutamic acid decarboxylase (GAD; Fig. 5D), a marker for GABAergic synapses (the major type of inhibitory synapses in the brain). In some neurons $\alpha$-actinin- 2 is present in elongated clusters in dendritic shafts, but these shaft clusters do not correspond to synaptic sites (Rao and Craig, unpublished observations). The absence of immunocolocalization between $\alpha$-actinin-2 and GAD is confirmed in vivo by double labeling of the cerebral cortex (Fig. $5 E-G$ ). Thus, $\alpha$-actinin-2 appears to be concentrated specifically in excitatory glutamatergic synapses, consistent with its localization in dendritic spines. 


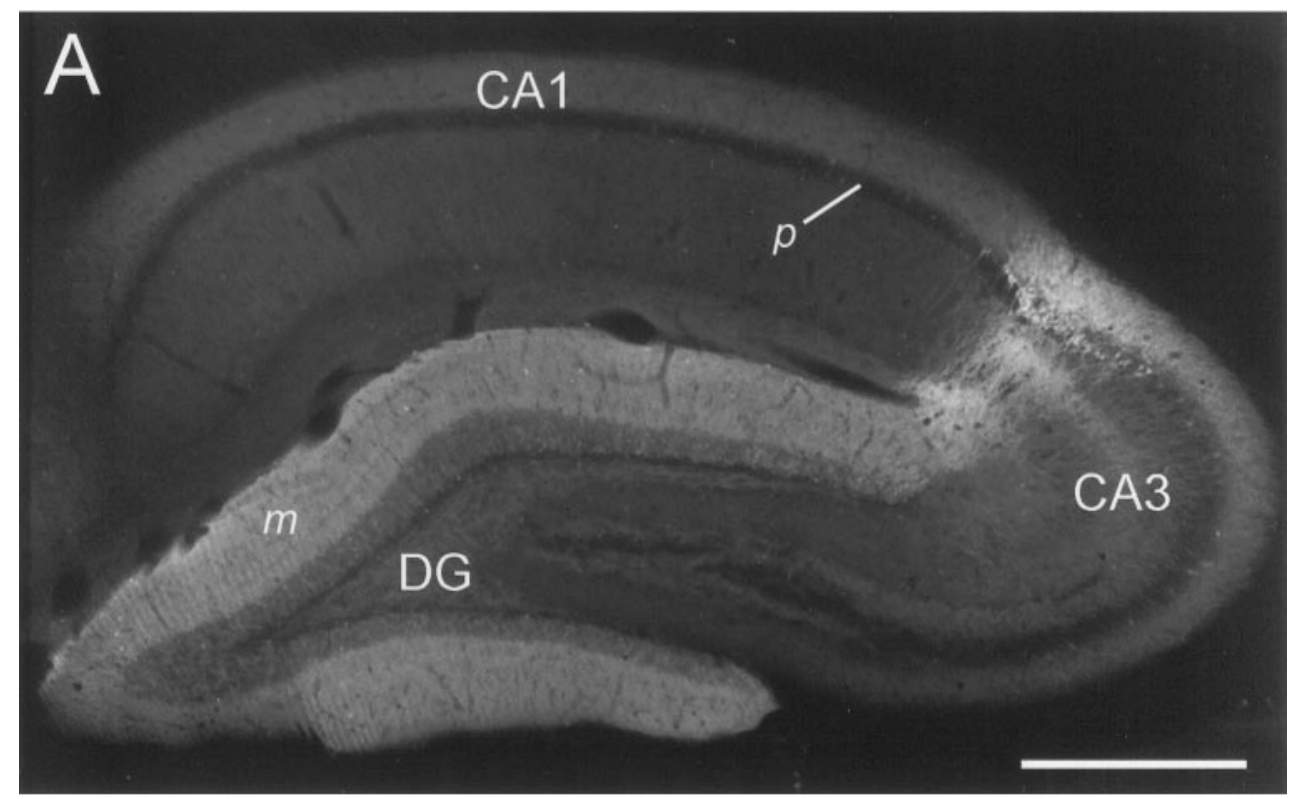

Figure 4. Differential regional expression of $\alpha$-actinin-2 protein in the hippocampal formation. $A, \mathrm{DAB}$ histochemistry showing $\alpha$-actinin-2 immunostaining pattern in hippocampus. $\alpha$-Actinin- 2 protein is expressed throughout the dendritic fields of all regions, but staining is strongest in the molecular layer of dentate gyrus and in area CA2. The negative image of the photomicrograph is shown to improve contrast. $B$, Fluorescence immunocytochemistry showing the dashed line pattern of $\alpha$-actinin-2 immunostaining seen in hippocampus, interspersed among the cell bodies of the pyramidal cell layer in CA1. $C$, High resolution confocal image of $\alpha$-actinin-2 immunostaining showing bright puncta on the cell bodies and apical dendrites of CA3 pyramidal cells. Bright puncta are also present on basal dendrites of CA3 pyramidal cells (data not shown). $D G$, Dentate gyrus; $m$, molecular layer; $p$, stratum pyramidale; $s l$, stratum lucidum; so, stratum oriens; $s r$, stratum radiatum. Scale bars: $A, 500 \mu \mathrm{m} ; B, 50 \mu \mathrm{m} ; C, 30 \mu \mathrm{m}$.
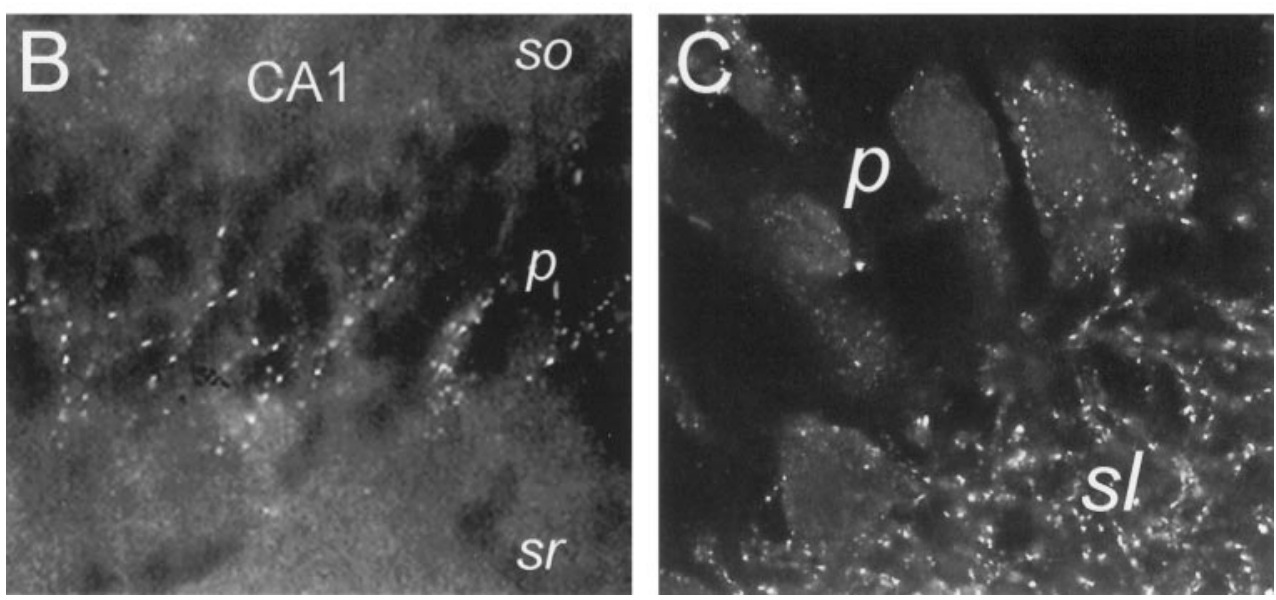

\section{Ultrastructural localization of $\alpha$-actinin-2}

The highest level of resolution in immunolocalization is afforded by immunogold labeling viewed by electron microscopy. Immunogold studies with 4B2 antibodies revealed $\alpha$-actinin-2 to be mainly associated with the postsynaptic density and postsynaptic membrane of numerous asymmetric synapses (Fig. 6A-E); symmetric synapses were labeled weakly if at all (data not shown). In dendritic spines, labeling was also commonly seen over microfilaments and the spine apparatus (Fig. 6A-C). In addition, labeling could be seen adjacent to microtubules in dendritic shafts (Fig. $6 F$ ).

Immunoperoxidase staining was qualitatively similar to immunogold labeling, although subsynaptic labeling was more abundant in axospinous synapses, often completely filling the cytoplasm of spines, possibly because of diffusion of the reaction product. By combining pre-embedding immunoperoxidase staining for $\alpha$-actinin-2 with postembedding immunogold labeling for NR1, we observed frequent colocalization (Fig. 7A); this was most prominent in axospinous synapses. Colocalization at asymmetric synapses was also apparent between $\alpha$-actinin- 2 and GKAP, a postsynaptic density protein at excitatory synapses that interacts directly with the PSD-95/synapse-associated protein (SAP)-90 family of putative ion channel-clustering proteins (Kim et al., 1997; Naisbitt et al., 1997) (Fig. 7B-D). The localization of $\alpha$-actinin- 2 at the PSD, as revealed by immunogold EM, indicates that $\alpha$-actinin- 2 is appropriately positioned to interact directly with NMDA receptors.

\section{DISCUSSION}

In our initial characterization of $\alpha$-actinin- 2 interactions with NMDA receptors, we provided evidence with light microscopy that $\alpha$-actinin- 2 is concentrated in synapses of cultured hippocampal neurons, as well as biochemical evidence that it is a core component of PSD fractions (Wyszynski et al., 1997). In the present report, we show that $\alpha$-actinin-2 is selective for glutamatergic synapses. Moreover, using immunogold EM in the intact brain, we demonstrate that $\alpha$-actinin- 2 is indeed concentrated at the PSD of asymmetric synapses and that it may be found at synapses also expressing NR1. These ultrastructural findings indicate that $\alpha$-actinin- 2 is close enough to bind directly to NR1 at postsynaptic sites. Together with previous data suggesting biochemical association of NR1 and $\alpha$-actinin-2 (Wyszynski et al., 1997), these EM results strengthen the idea that $\alpha$-actinin-2 functions in the synapse as an anchoring protein linking NMDA receptors to the submembrane actin cytoskeleton.

$\alpha$-Actinin-2 is not exclusively localized to the PSD, however. Subsynaptic $\alpha$-actinin-2 labeling was found associated with mi- 

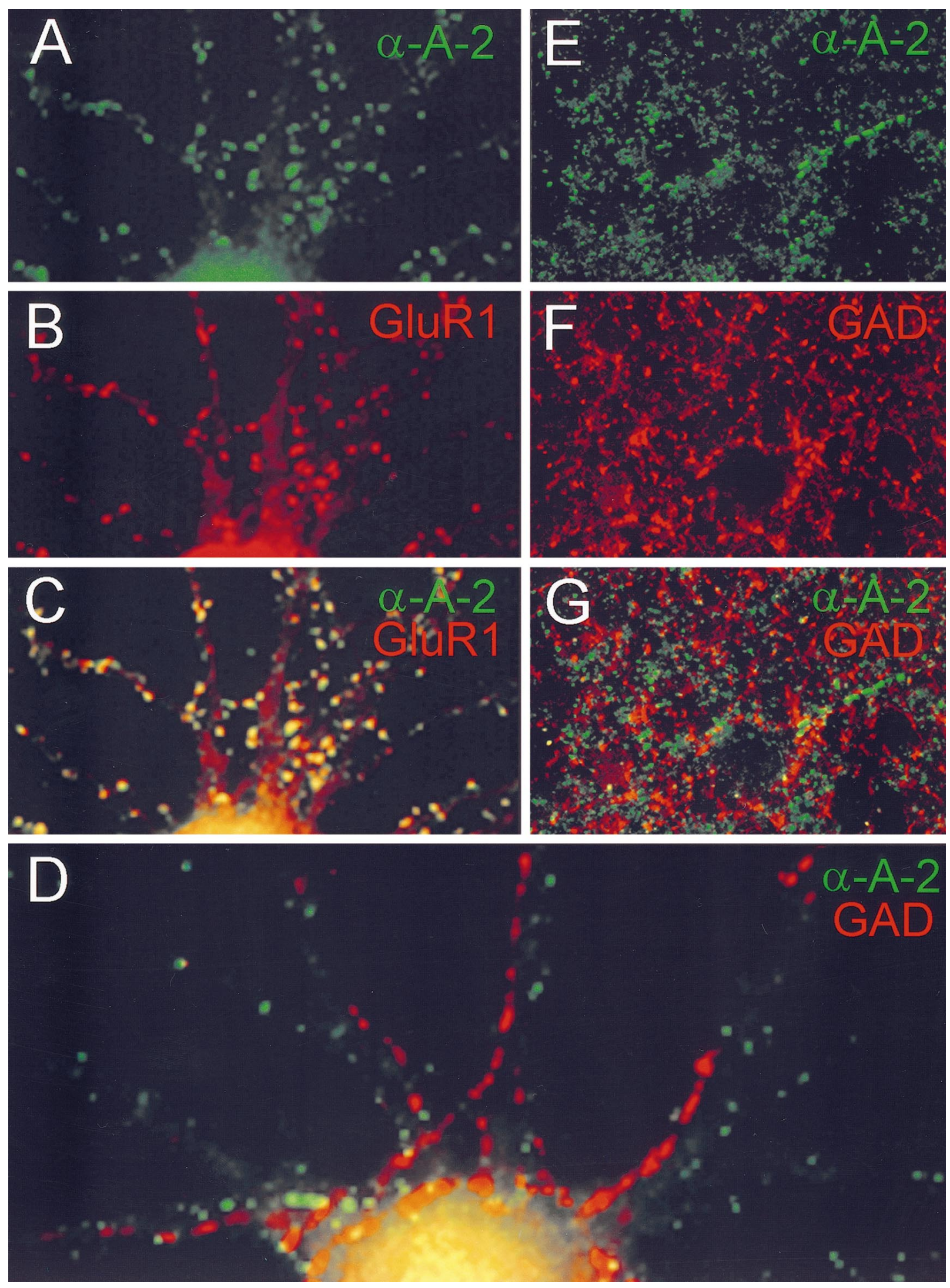

Figure 5. $\alpha$-Actinin-2 protein is specifically localized to excitatory synapses and is absent from inhibitory synapses. $A-G$, Colocalization of $\alpha$-actinin-2 immunoreactivity with GluR1 in cultured hippocampal neurons $(A-C)$, and noncolocalization of $\alpha$-actinin-2 and GAD in cultured hippocampal neurons $(D)$ and in cerebral cortex $(E-G)$. For $E-G$, the cortical surface is located to the left. $\alpha$-Actinin-2 is visualized by FITC secondary antibody ( green), and GluR1 and GAD are visualized by Cy3 secondary antibody (red). Composite images $(C, D, G)$ show colocalization of signals as yellow. 

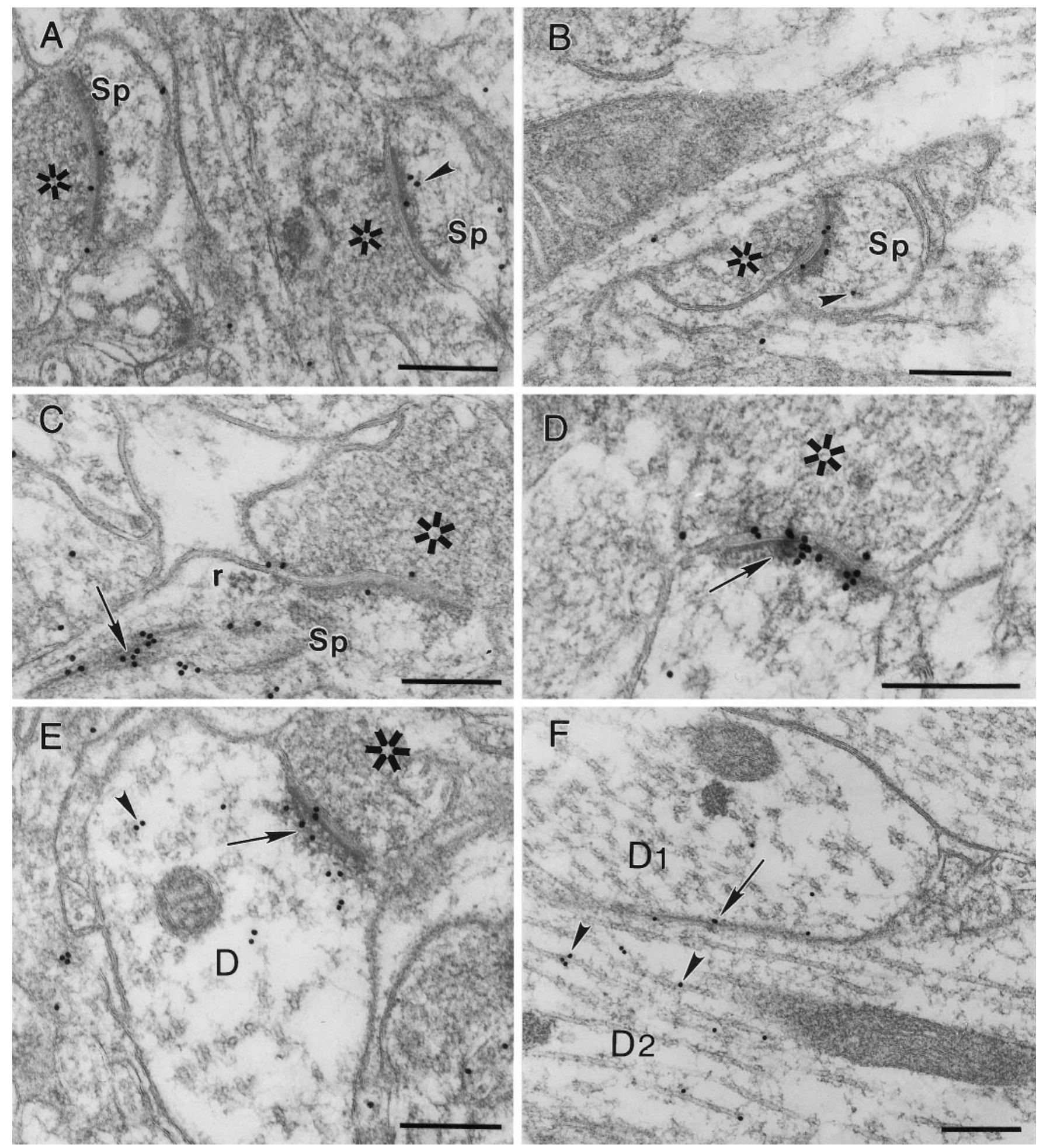

Figure 6. Immunogold labeling (18 nm gold particles) for $\alpha$-actinin-2 in postsynaptic densities of asymmetric synapses. $A, B$, Axospinous synapses are shown; arrowheads point to subsynaptic labeling associated with microfilaments in dendritic spines. $C$, Arrow denotes dense labeling over the spine apparatus. $D$, Arrow denotes prominent gold labeling within the postsynaptic density. $E, F$, Arrowheads show $\alpha$-actinin-2 labeling adjacent to microtubules in dendritic shafts; arrow in $E$ points to labeling over postsynaptic density of an axodendritic synapse; arrow in $F$ points to immunogold over dendrodendritic membrane apposition. $S p$, Spine; $r$, ribosomal complex; D1, D2, two adjacent dendrites; asterisks mark presynaptic terminals. Scale bars, $250 \mathrm{~nm}$.

crofilaments and the spine apparatus in dendritic spines. In addition, $\alpha$-actinin-2 labeling was detected in dendritic shafts adjacent to microtubules and sometimes at sites of membrane contact between dendrites. Some presynaptic expression of $\alpha$-actinin-2 can also not be excluded given the $\sim 10-20 \mathrm{~nm}$ error inherent in immunogold localization. However, pre-embedding immunoperoxidase labeling also supported a predominantly postsynaptic concentration of $\alpha$-actinin-2. Thus $\alpha$-actinin-2 differs from other 

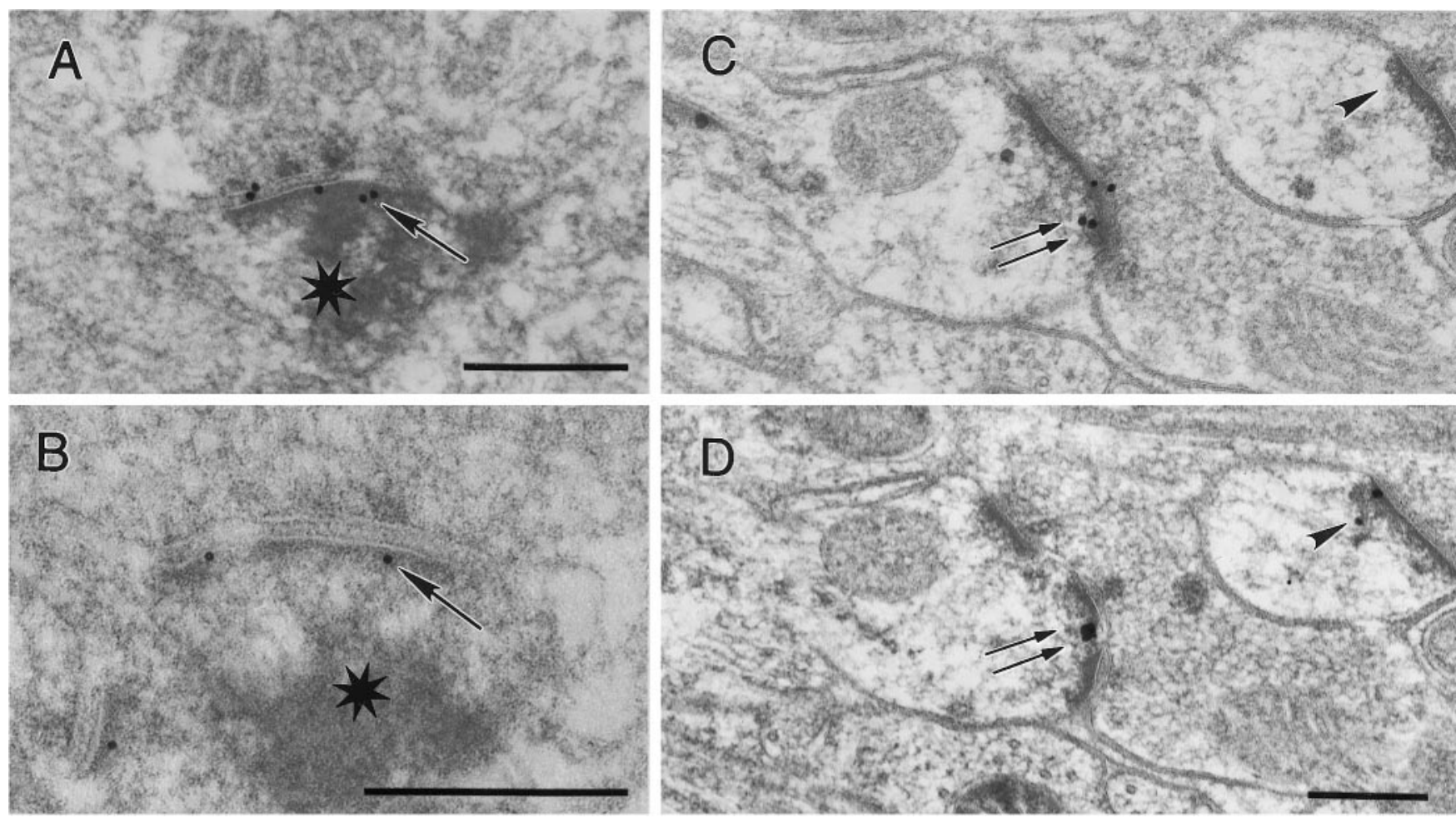

Figure 7. Colocalization of $\alpha$-actinin-2 with NR1 $(A)$ and GKAP $(B-D)$. $A$, Postembedding immunogold labeling (18 $\mathrm{nm})$ for NR1 is on synapse stained also for $\alpha$-actinin-2 with pre-embedding immunoperoxidase (the star marks postsynaptic electron-dense diaminobenzidine reaction product). $B$, Immunogold labeling for GKAP (12 nm gold particles) over postsynaptic density of $\alpha$-actinin-2-positive profile is shown. $C, D$, Serial thin sections were mounted on different grids and processed with silver-intensified immunogold for $\alpha$-actinin-2 $(C)$ or GKAP $(D)$. One synapse is positive for both antigens (double arrows); the other is positive for only GKAP (arrowheads on right). Scale bars, $250 \mathrm{~nm} ; C$ and $D$ are to the same scale.

PSD components [such as PSD-95 or GKAP (Naisbitt et al., 1997)] in showing relatively widespread subcellular distribution in neurons in addition to its accumulation at the PSD. This is not surprising given that the $\alpha$-actinins are actin-binding proteins found in many cell types and at a variety of cell junctions in non-neural cells.

The mechanism by which $\alpha$-actinin-2 is concentrated at synapses remains to be determined. Two known binding partners of $\alpha$-actinin-2, NMDA receptors and F-actin, are concentrated in the PSD and could result in its recruitment to postsynaptic sites. We found no detectable interaction between $\alpha$-actinin-2 and the PSD-95 family of synaptic proteins (M. Wyszynski and M. Sheng, unpublished observations), despite a C-terminal peptide sequence in $\alpha$-actinin-2 (-ETDL) that resembles known PDZ domain-binding motifs. We speculate that the $\alpha$-actinin-2 C terminal may bind to another PDZ-containing protein in synapses.

$\alpha$-Actinins are known actin-binding molecules, and actin is concentrated in dendritic spines, constituting a major component of brain postsynaptic densities (Matus et al., 1982; Hammonds, 1987; Byers et al., 1989). Because of its ability to cross-link actin filaments, $\alpha$-actinin- 2 could be an important structural component of the postsynaptic cytoskeleton. Interestingly, $\mathrm{Ca}^{2+}$ inhibits the actin-binding activity of $\alpha$-actinin purified from nonmuscle tissues including brain (Duhaiman and Bamburg, 1984). Calcium inhibition of actin cross-linking by $\alpha$-actinin- 2 could be a possible mechanism contributing to activity-dependent remodeling of the postsynaptic actin cytoskeleton. In contrast to $\mathrm{Ca}^{2+}$ effects, $\alpha$-actinin binding to F-actin is stimulated by PIP $_{2}$ (Fukami et al., 1992), a phospholipid second messenger the synthesis of which is regulated by RhoA, a small GTPase important in cytoskeletal regulation. Bidirectional control of $\alpha$-actinin-actin interactions via $\mathrm{Ca}^{2+}$ and $\mathrm{PIP}_{2}$ signals could contribute to cytoskeletal remodeling during activity-dependent structural plasticity of synapses.

The direct interaction between $\alpha$-actinin- 2 and NMDA receptor subunits represents an attractive mechanism for connecting NMDA receptors to postsynaptic actin filaments. Such a link has been implied by electrophysiological studies showing a dependence of NMDA receptor function on the integrity of the actin cytoskeleton (Rosenmund and Westbrook, 1993). Intriguingly, NMDA receptor anchoring to actin may be dynamically regulated, because $\alpha$-actinin-2 binding to NR1 is directly antagonized by $\mathrm{Ca}^{2+}$ /calmodulin in vitro (Wyszynski et al., 1997). Thus $\mathrm{Ca}^{2+}$ can potentially regulate NMDA receptor attachment to actin via two mechanisms, displacement of $\alpha$-actinin-2 from NR1 by calmodulin and inhibition of the actin-binding activity of $\alpha$-actinin. It is possible that both of these mechanisms could contribute to $\mathrm{Ca}^{2+}$-dependent inactivation of NMDA receptors (Rosenmund and Westbrook, 1993; Ehlers et al., 1996; Krupp et al., 1996). Thus $\alpha$-actinin- 2 may play a role in both the localization and $\mathrm{Ca}^{2+}$ modulation of NMDA receptors.

The differential regional expression of $\alpha$-actinin- 2 in rat brain suggests that glutamatergic synapses in distinct parts of the brain may differ in terms of their $\alpha$-actinin- 2 content. This finding emphasizes the heterogeneity of excitatory synapses with respect to molecular composition. Whether this reflects a functional heterogeneity of glutamatergic synapses remains to be determined. $\alpha$-Actinin- 2 exists at very low or undetectable levels in cerebellar granule cells, suggesting that NMDA receptors in this region are less likely to interact with $\alpha$-actinin-2. In the hippocam- 
pus, NMDA receptor function may be different in CA1 compared with the dentate gyrus because of differential interactions with $\alpha$-actinin-2. In this context, it is intriguing that the CA1 region, the most sensitive to NMDA receptor-mediated excitotoxicity, expresses low levels of $\alpha$-actinin-2.

Outside of the brain, $\alpha$-actinins are concentrated at the neuromuscular junction (Bloch and Hall, 1983), although there is no evidence that $\alpha$-actinin interacts with acetylcholine receptors in this model peripheral synapse. In addition to postsynaptic sites, $\alpha$-actinins are known to accumulate at other cell junctions, most notably at focal adhesions, the sites of contact between cultured cells and the extracellular matrix (Clark and Brugge, 1995). In focal adhesions, $\alpha$-actinin binds through its rod domain directly to the cytoplasmic tail of $\beta 1$-integrins (Otey et al., 1990), thus providing another example of a direct $\alpha$-actinin interaction with an integral membrane protein. The linkage of integrins to actin by $\alpha$-actinin is thought to play a role in nucleating the integrindirected cytoskeletal-signaling complex at focal contacts (Clark and Brugge, 1995). Focal adhesions and synapses both represent dynamic sites of membrane specialization where actin filaments converge, where specific extracellular matrix contacts are made, and where signaling molecules including tyrosine kinases are highly concentrated (Clark and Brugge, 1995). The finding that $\alpha$-actinin localizes to synaptic junctions reveals that there are molecular as well as organizational similarities between synapses and focal contacts.

Evidence converging from several lines of work is beginning to reveal the complexity of the interactions of NMDA receptors with cytoskeleton-associated proteins. Because NR2 subunits of NMDA receptors bind directly to the PSD-95 family of channelclustering molecules, the interaction between $\alpha$-actinin- 2 and NR1 emphasizes that heteromeric membrane receptors may use multiple mechanisms to interact with the subsynaptic cytoskeleton and with postsynaptic-signaling molecules.

\section{REFERENCES}

Beggs AH, Byers TJ, Knoll JHM, Boyce FM, Bruns GAP, Kunkel LM (1992) Cloning and characterization of two human skeletal muscle $\alpha$-actinin genes located on chromosomes 1 and 11. J Biol Chem 267:9281-9288.

Bliss TVP, Collingridge GL (1993) A synaptic model of memory: longterm potentiation in the hippocampus. Nature 361:31-39.

Bloch R, Hall Z (1983) Cytoskeletal components of the vertebrate neuromuscular junction: vinculin, alpha-actinin, and filamin. J Cell Biol 97:217-223.

Byers TJ, Husain-Chishti A, Dubreuil RR, Branton D, Goldstein LS (1989) Sequence similarity of the amino-terminal domain of drosophila beta spectrin to alpha-actinin and dystrophin. J Cell Biol 109:1633-1641.

Cho K-O, Hunt CA, Kennedy MB (1992) The rat brain postsynaptic density fraction contains a homolog of the drosophila discs-large tumor suppressor protein. Neuron 9:929-942.

Choi DW (1995) Calcium: still center-stage in hypoxic-ischemic neuronal death. Trends Neurosci 18:58-60.

Clark EA, Brugge JS (1995) Integrins and signal transduction pathways: the road taken. Science 268:233-239.

Constantine-Paton M, Cline HT, Debski E (1990) Patterned activity, synaptic convergence, and the NMDA receptor in developing visual pathways. Annu Rev Neurosci 13:129-154.
Duhaiman AS, Bamburg JR (1984) Isolation of brain $\alpha$-actinin. Its characterization and a comparison of its properties with those of muscle $\alpha$-actinins. Biochemistry 23:1600-1608.

Ehlers MD, Zhang S, Bernhardt JP, Huganir RL (1996) Inactivation of NMDA receptors by direct interaction of calmodulin with the NR1 subunit. Cell 84:745-755.

Fukami K, Furuhashi K, Inagaki M, Endo T, Hatano S, Takenawa T (1992) Requirement of phosphatidylinositol 4,5-bisphosphate for $\alpha$-actinin function. Nature 359:150-152.

Goslin K, Banker G (1991) Culturing nerve cells, pp 251-281. Cambridge, MA: MIT.

Hammonds RG (1987) Protein sequence of DMD gene is related to actin-binding domain of $\alpha$-actinin. Cell 51:1.

Kim E, Niethammer M, Rothschild A, Jan YN, Sheng M (1995) Clustering of shaker-type $\mathrm{K}^{+}$channels by interaction with a family of membrane-associated guanylate kinases. Nature 378:85-88.

Kim E, Cho K-O, Rothschild A, Sheng M (1996) Heteromultimerization and NMDA receptor-clustering activity of chapsyn-110, a member of the PSD-95 family of proteins. Neuron 17:103-113.

Kim E, Naisbitt S, Hsueh Y-P, Rao A, Rothschild A, Craig AM, Sheng M (1997) GKAP, a novel synaptic protein that interacts with the guanylate kinase-like domain of the PSD-95/SAP90 family of channel clustering molecules. J Cell Biol 136:669-678.

Kornau H-C, Schenker LT, Kennedy MB, Seeburg PH (1995) Domain interaction between NMDA receptor subunits and the postsynaptic density protein PSD-95. Science 269:1737-1740.

Krupp JJ, Vissel B, Heinemann SF, Westbrook GL (1996) Calciumdependent inactivation of recombinant $N$-methyl-D-aspartate receptors is NR2 subunit specific. Mol Pharmacol 50:1680-1688.

Matus A, Ackermann M, Pehling G, Byers HR, Fujiwara K (1982) High actin concentrations in brain dendritic spines and postsynaptic densities. Proc Natl Acad Sci USA 79:7590-7594.

Naisbitt S, Kim E, Weinberg RJ, Rao A, Yang F-C, Craig AM, Sheng M (1997) Characterization of guanylate kinase-associated protein, a postsynaptic density protein at excitatory synapses that interacts directly with postsynaptic density-95/synapse-associated protein 90 . J Neurosci 17:5687-5696.

Niethammer M, Kim E, Sheng M (1996) Interaction between the C-terminus of NMDA receptor subunits and multiple members of the PSD-95 family of membrane-associated guanylate kinases. J Neurosci 16:2157-2163.

Otey CA, Pavalko FM, Burridge K (1990) An interaction between $\alpha$-actinin and the $\beta_{1}$ integrin subunit in vitro. J Cell Biol 111:721-729.

Paoletti P, Ascher P (1994) Mechanosensitivity of NMDA receptors in cultured mouse central neurons. Neuron 13:645-655.

Petralia RS, Yokotani N, Wenthold RJ (1994) Light and electron microscope distribution of the NMDA receptor subunit NMDAR1 in the rat nervous system using a selective anti-peptide antibody. J Neurosci 14:667-696.

Phend KD, Rustioni A, Weinberg RJ (1995) An osmium-free method of Epon embedment that preserves both ultrastructure and antigenicity for postembedding immunocytochemistry. J Histochem Cytochem 43:283-292.

Rosenmund C, Westbrook GL (1993) Calcium-induced actin depolymerization reduces NMDA channel activity. Neuron 10:805-814.

Sheng M, Kim E (1996) Ion channel associated proteins. Curr Opin Neurobiol 6:602-608.

Sheng M, Cummings J, Roldan LA, Jan YN, Jan LY (1994) Changing subunit composition of heteromeric NMDA receptors during development of rat cortex. Nature 368:144-147.

Wyszynski M, Lin J, Rao A, Nigh E, Beggs AH, Craig AM, Sheng M (1997) Competitive binding of $\alpha$-actinin and calmodulin to the NMDA receptor. Nature 385:439-442. 